\title{
Desempenho da cultura do milho implantada sobre resíduos culturais de leguminosas de verão em sistema plantio direto
}

\author{
Corn crop sown during summertime under leguminous residues \\ in a no-tillage system
}

\author{
Danielle Medina Rosa ${ }^{1 *}$; Lúcia Helena Pereira Nóbrega ${ }^{2}$; Gislaine Piccolo de \\ Lima $^{3}$; Márcia Maria Mauli ${ }^{4}$
}

\begin{abstract}
Resumo
O sistema plantio direto é o sistema agrícola mais próximo da sustentabilidade e com menor impacto ambiental. A rotação de culturas, em sua forma correta, inclui a utilização de adubação verde; e as leguminosas são inseridas neste sistema por trazerem uma série de benefícios. Neste contexto, o presente estudo testou plantas leguminosas como cobertura do solo em sistema plantio direto sobre o crescimento, produtividade e qualidade de sementes de milho, visando alternativas que contribuam para a sustentabilidade do agroecossistema e permitam a adoção racional da adubação verde em unidades de produção. O experimento foi realizado em campo, com as espécies leguminosas feijão guandu anão, mucuna anã e estilosantes, semeadas em outubro de $2007 \mathrm{em}$ parcelas de 4x5 m, com cinco repetições. Aos 90 dias após a semeadura as plantas de cobertura foram roçadas e o milho semeado sobre os resíduos 15 dias após o manejo. Foram realizadas avaliações da estatura das plantas durante o desenvolvimento da cultura produtividade de grãos e qualidade fisiológica de sementes. O delineamento experimental foi inteiramente casualizado e as médias foram comparadas por Scott-Knott a 5\% de significância. Aos 60 dias após a semeadura da cultura do milho, os tratamentos com mucuna anã e feijão guandu anão resultaram em maiores alturas de plantas. Nos demais parâmetros analisados os tratamentos não diferiram, demonstrando que estes não interferem sobre a cultura do milho, sendo alternativa para o manejo integrado de espécies na prática de adubação verde de verão e rotação de cultura no sistema plantio direto.
\end{abstract}

Palavras chave: Rotação de culturas, adubação verde, safrinha

\begin{abstract}
The no-tillage system management is considered as an agricultural system very close to sustainability, since it causes less impact to the environment. The crops rotation, when well managed, includes the use of green manure; and leguminous are included in this system as they bring a number of benefits. This context, the study aimed tested leguminous as cover plants on soil with a no-tillage system regarding the growth, yield and maize seeds quality. This decision-making looks for alternatives that contribute for the agroecosystem sustainability, since they allow rational adoption of green manure in production units. The experiment was carried out in the field with leguminous species dwarf mucuna beans, dwarf pigeon pea and stylosanthes, sown in October 2007, in 4 × 5 m plots, with five replications. At 90 days after the cover crops sowing, the leguminous plants were grazed and corn plants were sown 15 days after grazing on waste. The plants heights were determined during the culture development. At the laboratory, after
\end{abstract}

\footnotetext{
Bióloga, Doutoranda do curso de pós-graduação em Engenharia Agrícola da Universidade Estadual do Oeste do Paraná, UNIOESTE, Cascavel, PR. E-mail: danimrosa@yahoo.com.br

2 Prof Associada do curso de pós-graduação em Engenharia Agrícola, UNIOESTE. E-mail: 1hpn@unioeste.br

3 Bióloga, Doutoranda do curso de pós-graduação em Engenharia Agrícola, UNIOESTE. E-mail: gisalipi@yahoo.com.br

4 Bióloga, Doutoranda do curso de pós-graduação em Engenharia Agrícola, UNIOESTE. E-mail: marcia.m.mauli@yahoo.com.br

* Autor para correspondência
} 
harvest, the productivity and physiological quality of seeds were determined. The experimental design was completely randomized and the averages were compared by the Scott-Knott test at $5 \%$ of significance. At 60 days after the maize crop sowing, the treatments with dwarf mucuna beans and dwarf pigeon pea showed higher heights. The other analyzed parameters did not differ among themselves, showing that the treatments not interfere on the maize crop. Actually, it is an alternative to the integrated management of species concerning the summer green manure and crop rotation in no-tillage system.

Key words: Crops rotation, green manure, second harvest

\section{Introdução}

A agricultura moderna não tem por finalidade somente a produtividade e rentabilidade, mas visa também à preservação ambiental. Para que estes objetivos sejam alcançados é necessário o manejo agrícola adequado, que gere sustentabilidade do sistema. Weih etal. (2008) definiram sustentabilidade na agricultura como aumento da utilização de técnicas ecológicas. A principal técnica relacionada à sustentabilidade, que mantém a fertilidade e vida do solo, é o plantio direto (MESCHEDE, 2006), o qual tem como requisito, adequada cobertura do solo (MENEZES; LEANDRO, 2004), sendo sua introdução um dos maiores avanços no processo produtivo da agricultura brasileira (LOPES et al., 2009).

De acordo com Christoffoleti et al. (2007), o sistema plantio direto é baseado em manter a superfície do solo com resíduos de plantas, com o mínimo de distúrbio nas camadas superficiais do solo. Dentro deste contexto, um sistema plantio direto com qualidade exige planejamento da sucessão de culturas no tempo e no espaço (MEDEIROS; CALEGARI, 2006), ou seja, adequada rotação de culturas, em que as plantas utilizadas mantenham um ciclo que garanta melhoria ao sistema, sem prejudicar a cultura principal e utilizando a rotação de culturas de forma correta (PAULUS; MÜLLER; BARCELLOS, 2000).

A prática de rotação de culturas, substituindo a sucessão soja-trigo, é importante no controle de pragas, doenças e plantas invasoras, assim como no manejo da fertilidade do solo, pela capacidade de reciclar os nutrientes minerais da camada arável e os que tenham percolado para horizontes abaixo dela (BORKERT et al., 2003).

Segundo Medeiros e Calegari (2006) as plantas de cobertura permitem, além da melhoria e/ou conservação do solo e matéria orgânica, viabilidade econômica, pois, trazem aumento no rendimento das culturas subseqüentes, quando inseridas em um sistema de rotação de cultivos adequado.

Plantas leguminosas e não leguminosas são usadas para produção de adubos verdes (TEJADA; HERNANDEZ; GARCIA, 2008). As espécies mais utilizadas como cobertura vegetal são as pertencentes à família das gramíneas (Poaceae) e das leguminosas (Fabaceae). As gramíneas são as que produzem resíduos com maior permanência e são usadas quando o objetivo é a manutenção da cobertura do solo; contudo, são das leguminosas os resíduos de maior qualidade e com os melhores resultados, sendo usadas quando o objetivo é a incorporação de resíduos no solo (AMBROSANO et al., 2005; MENEZES E LEANDRO, 2004), mesmo apresentando efeitos físicos menos prolongados no solo (CALEGARI et al., 1992).

O uso de adubos verdes, capazes de realizar a fixação biológica de nitrogênio de forma eficiente, pode contribuir para a viabilidade econômica e sustentabilidade dos sistemas de produção (PERIN et al., 2004), porque fixam o nitrogênio, fertilizante mais caro na produção agrícola, o qual é aproveitado pela cultura subseqüente (SOUZA; PIRES, 2002). Isso acontece na medida em que a fertilidade do solo é preservada e há diminuição no uso de fertilizantes. Borkert et al. (2003), em estudos sobre nutrientes minerais na biomassa da parte aérea em culturas de cobertura de solo, observaram que as leguminosas ervilhaca (Vicia sativa), mucuna-preta (Mucuna 
aterrina), tremoço (Lupinus albus) e guandu (Cajanus cajan) reciclam grande quantidade de nitrogênio.

A reciclagem de nutrientes e o aproveitamento dos restos de culturas como fonte de adubo orgânico são relevantes para o adequado manejo da fertilidade do solo. A versatilidade do milho para inclusão em rotação de cultura já é amplamente conhecida, sendo uma planta de raízes fasciculadas e de alta exigência em nitrogênio, deve ser incluído em rotação com leguminosas (IAPAR, 1991).

De acordo com Fancelli e Dourado Neto (2000), o emprego de adubos verdes antecedendo a cultura do milho pode contribuir para reduzir a necessidade de adubação de cobertura, perfazendo economia de 40 a $80 \mathrm{~kg} \mathrm{ha}^{-1}$ de nitrogênio. Além disso, segundo Tokura e Nóbrega (2006), na semeadura direta, os resíduos vegetais presentes na cobertura têm importância fundamental e podem apresentar efeitos alelopáticos sobre as plantas invasoras.

Neste contexto, o presente estudo visou avaliar o efeito de plantas leguminosas de verão como cobertura do solo em sistema plantio direto sobre o crescimento, produtividade e qualidade de sementes de milho, como alternativa para garantir a sustentabilidade do agroecossistema e permitir a adoção racional da adubação verde em unidades de produção.

\section{Material e Métodos}

O experimento foi realizado em uma propriedade agrícola, localizada na região Oeste do Paraná, no município de Braganey, nas coordenadas 24⒌'08" $\mathrm{S}$ de latitude e $53^{\circ} 07^{\prime} 15^{\prime}$ ' W de longitude, no ano agrícola de 2007/2008. O solo é Latossolo Vermelho eutroférrico, a região tem precipitação média anual de $1.600 \mathrm{~mm}$ e temperatura média anual de $20^{\circ} \mathrm{C}$.

Para a determinação da fertilidade e possível necessidade de correção, foi realizada análise química do solo. As amostras foram retiradas na profundidade de $0-20 \mathrm{~cm}$, antecedendo à semeadura das plantas de cobertura (Tabela 1).

Tabela 1. Teores de nutrientes determinados na análise química do solo antes da implantação das espécies leguminosas usadas como cobertura vegetal*.

\begin{tabular}{|c|c|c|c|c|c|c|c|c|}
\hline \multicolumn{9}{|c|}{ Variáveis } \\
\hline $\begin{array}{c}P \\
m g d^{-3}\end{array}$ & $\begin{array}{c}\mathrm{K}+ \\
\text { cmolc dm }^{-3}\end{array}$ & $\begin{array}{c}C \\
g \mathrm{dm}^{-3}\end{array}$ & $\begin{array}{c}\mathrm{Al}^{3+} \\
\text { cmolc. } \mathbf{d m}^{-3}\end{array}$ & $\begin{array}{c}\mathrm{Ca}^{2+} \\
\text { cmolc. } \mathbf{d m}^{-3}\end{array}$ & $\begin{array}{c}\mathrm{Mg}^{2+} \\
\text { cmolc } \cdot \mathrm{dm}^{-3}\end{array}$ & pH & $\begin{array}{c}\text { MO } \\
\text { g.dm-3 }\end{array}$ & $\begin{array}{c}\mathrm{H}^{+}+\mathrm{Al}^{3+} \\
\text { cmolc.dm }{ }^{-3}\end{array}$ \\
\hline 14,20 & 0,30 & 17,82 & 0,19 & 3,34 & 1,29 & 4,70 & 30,65 & 5,35 \\
\hline$\overline{\text { M. alto }}$ & Médio & Médio & Baixo & Médio & Alto & Baixo & & \\
\hline
\end{tabular}

* Análise realizada no laboratório de solos da Cooperativa Central de Pesquisa Agrícola (COODETEC).

A área experimental foi cultivada sob sistema plantio direto, com sucessão soja-trigo, por aproximadamente dez anos. O preparo do solo, neste experimento, ocorreu sob cultivo mínimo, em virtude da compactação em que se encontrava o solo.

As leguminosas mucuna anã [Mucuna deeringiana (Bort.) Merr], feijão guandu anão
(Cajanus cajan L.) e estilosantes (Stylosanthes capitata e macrocephala) foram semeadas nas quantidades de aproximadamente 200.000, 500.000 e 700.000 sementes viáveis $\mathrm{ha}^{-1}$, respectivamente, na área experimental, em outubro de 2007, em parcelas de 4 x $5 \mathrm{~m}$, com espaçamento de $1 \mathrm{~m}$ entre parcelas. A semeadura foi realizada a lanço e as sementes incorporadas 
ao solo com enxada, na profundidade aproximada de $2-3 \mathrm{~cm}$, sem adubação. Os tratamentos foram quatro, sendo três leguminosas e uma testemunha (pousio). Duas pulverizações foram realizadas com o inseticida metamidafós $\left(\right.$ Tamaron $^{\circledR}$ ), na dose $600 \mathrm{~mL} \mathrm{ha}^{-1}$, sobre as plantas de cobertura, principalmente para o controle da vaquinha (Diabrotica speciosa). $\mathrm{Na}$ testemunha foram realizados os mesmos procedimentos que nos demais tratamentos, porém, a área permaneceu sob pousio durante a realização do experimento com as plantas de cobertura (formação de vegetação natural), as principais invasoras encontradas na testemunha foram picão preto e corda de viola.

As leguminosas foram roçadas em fevereiro de 2008, com o auxílio de roçadora mecânica, rente ao solo, e a palhada correspondente ao tratamento permaneceu sobre a parcela. Amostras da parte aérea das espécies vegetais para determinação da massa seca foram colhidas, sendo retirada uma amostra de cada parcela de cada tratamento. Um quadro metálico de $0,25 \mathrm{~m}^{2}$ foi jogado aleatoriamente quatro vezes e após uniu-se as sub-amostras, formando uma amostra única. A massa seca foi determinada após secagem em estufa de circulação de ar a $60^{\circ} \mathrm{C}$ por 48 h. A massa seca das plantas de cobertura foi de 452, 488, 1131 e $272 \mathrm{~kg} \mathrm{ha}^{-1}$, para testemunha, mucuna anã, feijão guandu anão e estilosantes, respectivamente.

O híbrido de milho utilizado foi o Pioneer 30R32, característico para cultivo na safrinha. A semeadura foi com matraca, em fevereiro de 2008, sobre os restos vegetais das leguminosas, 15 dias após o corte, nas parcelas demarcadas, sob sistema plantio direto. $\mathrm{O}$ espaçamento entre linhas foi de $80 \mathrm{~cm}$, com cinco linhas por parcela, sendo consideradas linhas úteis as três linhas centrais e a densidade foi de 60.000 sementes ha ${ }^{-1}$. A adubação foi de $350 \mathrm{~kg} \mathrm{ha}^{-1}$, na semeadura, a lanço, da fórmula 10-20-20 (NPK) e $140 \mathrm{~kg} \mathrm{ha}^{-1}$ de uréia (60 $\mathrm{kg} \mathrm{ha}^{-1}$ de nitrogênio), em cobertura,
45 dias após a semeadura (estádio entre V6 e V8). Mensalmente, a altura de dez plantas de milho foi mensurada, considerando a distância do solo até a inserção da última folha emitida, aleatoriamente, em cada parcela.

Além disso, foi analisado a emergência de plântulas e o estande populacional aos 21 dias, considerando as linhas úteis, e calculada a porcentagem relativa da produção de milho entre os tratamentos comparados à testemunha.

A colheita do milho foi manual, nas três linhas centrais de cada parcela (linhas úteis), desprezando as bordaduras. As espigas de milho colhidas foram desempalhadas manualmente e processadas em debulhador manual, o qual provoca menos danos às sementes.

As sementes colhidas foram embaladas, identificadas e levadas ao laboratório, para determinação da produtividade, a qual foi corrigida para teor de água de $13 \%$ e os valores extrapolados para $\mathrm{kg} \mathrm{ha}^{-1}$.

A determinação da qualidade de sementes foi realizada no Laboratório de Avaliação de Sementes e Plantas (LASP) do Centro de Ciências Exatas e Tecnológicas (CCET) da Universidade Estadual do Oeste do Paraná, campus de Cascavel. Para o teste de germinação os resultados foram expressos em porcentagem (\%) de plântulas normais, anormais, sementes duras e mortas.

A qualidade das sementes de milho e das leguminosas foi determinada em laboratório, antes da implantação das culturas e após a colheita do milho. Sendo os resultados de germinação de $90 \%$ para mucuna anã, $86 \%$ para feijão guandu anão, 73\% para estilosantes e $97 \%$ para milho. Os testes empregados para determinação da qualidade de sementes foram os seguintes: teor de água, massa de 100 sementes, porcentagem de germinação e teste frio, todos seguindo as recomendações prescritas em Brasil (2009) e Marcos Filho, Cícero e Silva (1987). 
O delineamento experimental utilizado foi inteiramente casualizado, com cinco repetições por tratamento em campo e quatro repetições no laboratório. Os resultados obtidos foram submetidos à análise de variância e a comparação de médias foi realizada pelo teste de Scott-Knott a 5\% de significância. Os dados de germinação e teste frio foram transformados em $\sqrt{x}$.

\section{Resultados e Discussão}

$\mathrm{Na}$ Tabela 2 é apresentada a altura média das plantas de milho cultivadas sobre os resíduos das leguminosas mucuna anã, feijão guandu anão e estilosantes, referentes às avaliações aos 30, $60 \mathrm{e}$ 90 dias após a semeadura.

Tabela 2. Estatura média $(\mathrm{cm})$ das plantas de milho cultivadas sobre os resíduos culturais das leguminosas, referente a avaliações aos 30, 60 e 90 dias após a semeadura (DAS). Braganey (PR), 2007/2008.

\begin{tabular}{|c|c|c|c|}
\hline \multirow[b]{2}{*}{ Tratamento } & \multicolumn{3}{|c|}{ DAS } \\
\hline & 30 dias & 60 dias & 90 dias \\
\hline & \multicolumn{3}{|c|}{ 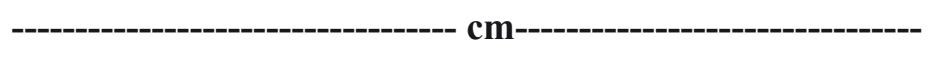 } \\
\hline Testemunha & 58,3 a & $140,7 \mathrm{~b}$ & $287,3 \mathrm{a}$ \\
\hline Mucuna anã & 59,5 a & $151,1 \mathrm{a}$ & $291,8 \mathrm{a}$ \\
\hline F. guandu anão & $60,0 \mathrm{a}$ & $154,4 \mathrm{a}$ & $287,5 \mathrm{a}$ \\
\hline Estilosantes & $55,2 \mathrm{a}$ & $136,8 \mathrm{~b}$ & 290,8 a \\
\hline Coef. De variação (\%) & 9,38 & 4,70 & 5,11 \\
\hline Média geral & 58 & 146 & 289 \\
\hline Valores de F & $0,77^{\mathrm{ns}}$ & $7,43^{*}$ & $0,12^{\text {ns }}$ \\
\hline
\end{tabular}

Médias seguidas pela mesma letra, na coluna, não diferem entre si pelo teste de Scott-Knott a $5 \%$ de probabilidade.

Não se verificou diferença na altura das plantas de milho aos 30 e 90 dias após a semeadura. Aos 60 dias, as plantas apresentaram maior altura nos tratamentos com feijão guandu anão e mucuna anã, respectivamente - enquanto a testemunha e estilosantes proporcionaram menor altura (Tabela 2), sem diferirem entre si. Nesta fase, a cultura encontrava-se em pleno desenvolvimento vegetativo (entre os estádios V8 e V9), provavelmente com maior demanda por nitrogênio. Segundo Boddey et al. (2010) é certo que as leguminosas que contribuem para a entrada de nitrogênio pela fixação biológica apresentem importante papel em promover acúmulo de carbono em solo sob plantio direto, o que pode ser devido à liberação lenta de nitrogênio dos resíduos na superfície, favorecendo o crescimento das raízes de milho. Este efeito pode influenciar, inclusive, na altura das plantas, fato este que pode explicar os resultados obtidos neste trabalho, aos 60 dias após a semeadura do milho.

Neste período, a cultura pode ter sofrido com estresse hídrico porque foi o momento em que ocorreu a menor precipitação do ciclo, em torno de $60 \mathrm{~mm}$ no mês segundo dados do SIMEPAR. Por isso, provavelmente, as plantas de milho submetidas ao tratamento com mucuna anã e feijão guandu anão, estavam mais vigorosas e resistiram melhor às condições ambientais adversas, porque essas duas espécies resultaram em maior cobertura vegetal sobre o solo e esta, favorece a manutenção da umidade do mesmo.

O comportamento do milho em seis sucessões de culturas foi estudado por Pasqualetto e Costa (2001). Os autores encontraram maior altura das plantas de milho após sucessão com guandu, sem 
que diferisse estatisticamente da soja (Glycine max), girassol (Helianthus annus) e milheto (Pennisetum glaucum). Neste trabalho, aos 60 dias após a semeadura, o milho em sucessão ao feijão guandu anão e mucuna anã, também apresentou a maior altura.
$\mathrm{Na}$ Tabela 3 são apresentadas as médias de produtividade de milho cultivado sob os resíduos culturais das leguminosas mucuna anã, feijão guandu anão, estilosantes e testemunha. A produtividade do milho não foi afetada pelos tratamentos avaliados.

Tabela 3. Estande aos 21 dias, produtividade de milho e porcentagem relativa de produção entre os tratamentos, com resíduos de leguminosas. Braganey (PR), 2007/2008.

\begin{tabular}{lccc}
\hline Tratamentos & Estande (21 dias) & Produtividade $\left(\mathbf{k g ~ h a}^{-1}\right)$ & Produção relativa \% \\
\hline Testemunha & $21 \mathrm{a}$ & $4777 \mathrm{a}$ & 100 \\
Mucuna anã & $24 \mathrm{a}$ & $4956 \mathrm{a}$ & 104 \\
F. guandu anão & $22 \mathrm{a}$ & $4831 \mathrm{a}$ & 101 \\
Estilosantes & $22 \mathrm{a}$ & $4418 \mathrm{a}$ & 92 \\
\hline Coef. de variação (\%) & 22,63 & 13,47 & - \\
Média geral & 22,36 & 4746 & - \\
Valores de F & $0,28^{\mathrm{ns}}$ & $0,65^{\mathrm{ns}}$ & - \\
\hline
\end{tabular}

Médias seguidas pela mesma letra, na coluna, não diferem entre si pelo teste de Scott-Knott a $5 \%$ de probabilidade.

Considerando percentuais de produtividade em relação à testemunha, o estilosantes foi o único tratamento em qual se verificou redução de $8 \%$ na produtividade comparado à testemunha (Tabela 3). O feijão guandu anão e a mucuna anã apresentaram aumento na produtividade em relação à testemunha, de 1 e $4 \%$, respectivamente.

Na safrinha 2007/2008, o Paraná obteve produção de $5.489 .330 \mathrm{t}$ em área de 1.512 .078 ha, correspondendo a aproximadamente $3630 \mathrm{~kg}$ ha $^{-1}$ (SEAB, 2008). A produtividade do milho safrinha, neste experimento, foi acima da média paranaense, possivelmente, por que as plantas de coberturas e mesmo a condição de pousio (testemunha), proporcionaram melhores condições para o desenvolvimento das plantas de milho, como por exemplo, a fixação e/ou ciclagem de nutrientes, resultando em maiores produtividades.

Em estudo semelhante, Bertin, Andrioli e Centurion (2005) pesquisaram plantas de cobertura em pré-safra ao milho sob plantio direto, em Latossolo Vermelho distrófico. As culturas estudadas foram milheto (Pennisetum americanum (L.) Leeke), crotalária juncea (Crotalaria juncea L.), guandu (Cajanus cajan (L.) Millsp), sorgo (Sorghum bicolor L. Moench), mucuna-preta (Mucuna aterrima (Piper e Tracy) Merr.), feijãode-porco (Canavalia ensiformis DC.), pousio (vegetação espontânea), lablabe (Dolichos lablab L.) e braquiária (Brachiaria brizantha (Hochst) Stapf). A cultura do milho, em sucessão à crotalária, apresentou maior produção de grãos $(7167 \mathrm{~kg}$ ha1). A crotalária é uma leguminosa, assim como as espécies de cobertura estudadas neste trabalho.

Carvalho et al. (2004) estudaram a cultura da soja em sucessão a adubos verdes nos sistemas plantio direto e convencional, em solo Latossolo Vermelho distroférrico na região Centro-Oeste. Entre os adubos verdes estudados estavam o guandu e a mucuna. Os autores concluíram que o cultivo dos adubos verdes na primavera não influenciou a produtividade da soja em sucessão, assim como no presente trabalho, em que não houve diferença na produtividade, neste caso, do milho safrinha. 
Heinrichs et al.(2005) encontraram produtividade de milho $20 \%$ maior que a testemunha, quando este foi cultivado após a leguminosa feijão de porco. A produtividade de grãos de milho não foi influenciada pelo cultivo consorciado com os demais adubos verdes, entre eles, mucuna anã, guandu anão e crotalária, assim como neste trabalho, em que não foi foi observada alteração.

$\mathrm{Na}$ Tabela 4 são apresentados os dados de porcentagem de germinação, vigor determinado pelo teste frio, massa de 100 sementes e teor de água de sementes de milho colhidas após o cultivo de plantas de cobertura de leguminosas mucuna anã, feijão guandu anão, estilosantes e testemunha.

Os dados de qualidade e do teor de água de sementes de milho demonstram que não houve diferença significativa entre os tratamentos, podendo-se inferir que os mesmos não afetaram a qualidade de sementes.

Tabela 4. Porcentagem de germinação de plântulas normais (\%), vigor determinado pelo teste frio (\%), massa de 100 sementes $(\mathrm{g})$ e teor de água (\%) de sementes de milho após resíduos com leguminosas. Braganey (PR), 2007/2008.

\begin{tabular}{|c|c|c|c|c|}
\hline$\overline{\text { Tratamentos }}$ & $\begin{array}{c}\text { Germinação } \\
---0\end{array}$ & Teste frio & $\begin{array}{c}\text { Massa de } 100 \text { sementes } \\
\text {---g--- }\end{array}$ & $\begin{array}{c}\text { Teor de água } \\
---\% \text {---- }\end{array}$ \\
\hline Testemunha & $97 \mathrm{a}$ & $97 \mathrm{a}$ & $40 \mathrm{a}$ & $17,0 \mathrm{a}$ \\
\hline Mucuna anã & $97 \mathrm{a}$ & $97 \mathrm{a}$ & $41 \mathrm{a}$ & $16,7 \mathrm{a}$ \\
\hline F. guandu anão & $95 \mathrm{a}$ & $94 \mathrm{a}$ & $41 \mathrm{a}$ & $16,4 \mathrm{a}$ \\
\hline Estilosantes & $98 \mathrm{a}$ & $97 \mathrm{a}$ & $40 \mathrm{a}$ & $17,4 \mathrm{a}$ \\
\hline Coef. de variação (\%) & 0,99 & 1,28 & 2,46 & 5,13 \\
\hline Média geral & 97 & 96 & 45 & 17 \\
\hline Valores de F & $1,43^{\mathrm{ns}}$ & $0,89^{\text {ns }}$ & $1,58^{\mathrm{ns}}$ & $1,27^{\mathrm{ns}}$ \\
\hline
\end{tabular}

Médias seguidas pela mesma letra, na coluna, não diferem entre si pelo teste de Scott-Knott a $5 \%$ de probabilidade. Os dados apresentados para germinação e teste frio são os obtidos das observações originais seguidos das letras obtidas na comparação de médias com a transformação em $\sqrt{x}$.

Os dados obtidos no teste de germinação e teste frio, para plântulas anormais e sementes duras, não foram significativos, por isso são apresentados apenas os dados de plântulas normais. Tanto para a germinação, como para o teste frio, os tratamentos não diferiram entre si (Tabela 4) como esperado, pois as plantas de cobertura são utilizadas para promover melhores condições químicas e físicas para o solo e não seria interessante que tivessem efeito prejudicial para a qualidade de sementes.

No entanto, a maioria dos trabalhos referentes a produtividade das culturas relacionadas com a utilização de plantas de cobertura e com o sistema plantio direto não relatam resultados e pesquisas com informações sobre a qualidade fisiológica das sementes produzidas nestas condições (NUNES et al., 2007).

A utilização de adubação verde de verão ou na entresafra (primavera), garante que a rotação de culturas seja realizada de forma adequada, assegurando as vantagens do uso da adubação verde, sendo a rotação de culturas uma ação básica para a viabilidade do sistema plantio direto. Não se verificou efeitos das plantas de cobertura na produtividade e qualidade de sementes de milho. Avaliações em curtos períodos de tempo podem não 
evidenciar todos os benefícios da rotação de culturas e da adubação verde, porém, aos 60 dias após a semeadura houve aumento da altura de plantas.

\section{Conclusões}

As espécies de cobertura não interferem na produtividade e a qualidade fisiológica de sementes de milho, sendo alternativa para o manejo integrado de espécies na prática de adubação verde de verão e rotação de cultura no sistema plantio direto.

\section{Referências}

AMBROSANO, E. J.; GUIRRADO, N.; ANTARELLAA, H.; SSETO, R.; MENDES, P. C. D.; ROSSI, F.; AMBROSANO, G. M. B.; SCHAMMAS, E. A.; JUNIOR, I. A.; FOLTRAN, D. E. Plantas para cobertura do solo e adubação verde aplicadas ao plantio direto. Informações Agronômicas: Potafós, Piracicaba, n. 112, p. 1-16, 2005. (Boletim técnico, n. 112).

BERTIN, E. G.; ANDRIOLI, I.; CENTURION, J. F. Plantas de cobertura em pré-safra ao milho em plantio direto. Acta Scientiarum Agronomy, Maringá, v. 27, n. 3, p. 379-386, 2005.

BODDEY, R. M.; JANTALIA, C. P.; CONCEICÃO, P. C.; ZANATTA, J. A.; BAYER, C.; MIELN ICZUK, J.; DIECKOW, J.; SANTOS, H. P.; DENARDIN, J. E.; AITA, C.; GIACOMINI, S. J.; ALVES, B. J. R.; SEG UNDO, U. Carbon accumulation at depth in Ferralsols under zero-till subtropical agriculture. Global Change Biology, v. 16, p. 784-795, 2010.

BORKERT, C. M.; AUDÊNCIO, C. A.; PEREIRA, J. E.; PEREIRA, R.; JUNIOR, A. O. Nutrientes minerais na biomassa da parte aérea em culturas de cobertura de solo. Pesquisa Agropecuária Brasileira, Brasília, v. 38, n. 1, p. 143-153, 2003.

BRASIL. Ministério da Agricultura, Pecuária e Abastecimento. Regras para análise de sementes. Brasília: Secretaria de Defesa Agropecuária, Mapa/ACS, 2009. 399 p.

CALEGARI, A.; MONDARDO, A.; BULISANI, E. A.; WILDNER, L. P.; COSTA, M. B. B. C.; ALCÂNTARA, P. B.; MIYASAKA, S.; AMADO, T. J. C. Adubo verde no sul do Brasil. Rio de Janeiro: ASPTA, 1992. 346 p.

CARVALHO, M. A. C.; SORATTO, R. P.; ATHAYDE, M. L. F.; ARF, O.; SÁ, M. E. Produtividade do milho em sucessão a adubos verdes no sistema de plantio direto e convencional. Pesquisa Agropecuária Brasileira, Brasília, v. 39, n. 1, p. 47-53, 2004.

CHRISTOFFOLETI, P. J.; CARVALHO, S. J. P.; LÓPEZ-OVEJERO, R. F.; NICOLAI, M.; HIDALGO, E.; SILVA, J. E. Conservation of natural resources in Brazilian agriculture: Implicatios on weed biology and management. Crop Protection, Oxford, v. 26, n. 3, p. 383-389, 2007.

FANCELLI, A. L.; DOURADO NETO, D. Produção de milho. Guaíba: Agropecuária, 2000. 360 p.

HEINRICHS, R.; VITTI, G. C.; MOREIRA， A.; FIGUEIREDO, P. A. M.; FANCELLI, A. L.; COREZZA, E. J. Características químicas de solo e rendimento de fitomassa de adubos verdes e de grãos de milho, decorrente do cultivo consorciado. Revista Brasileira de Ciência Solo, Viçosa, v. 29, n. 1, p. 71-79, 2005.

INSTITUTO AGRONÔMICO DO PARANÁ - IAPAR. A cultura do milho no Paraná. Londrina: IAPAR, 1991. 270 p. (Circular técnica, n. 68).

LOPES, A. S.; WIETHÖLTER, S.; GUILHERME, L. R. G.; SILVA, C. A. Sistema plantio direto: bases para o manejo da fertilidade do solo. 2009. Disponível em: $\quad<$ http://www.anda.org.br/boletinstecnicos.aspx.>. Acesso em: 26 jan. 2009.

MARCOS FILHO, J.; CICERO, S. M.; SILVA, W. R. Avaliação da qualidade de sementes. Piracicaba : FEALQ, 1987. $230 \mathrm{p}$.

MEDEIROS, G. B.; CALEGARI, A. Rotação de culturas. In: CASÃO JUNIOR, R.; SIQUEIRA, R.; MEHTA, Y. J.; PASSINI, J. J. Sistema plantio direto com qualidade. Londrina: IAPAR; Foz do Iguaçu: ITAIPU Binacional, p. 135-141, 2006.

MENEZES, L. A. S.; LEANDRO, W. M. Avaliação de espécies de coberturas do solo com potencial de uso em sistema de plantio direto. Pesquisa Agropecuária Tropical, Goiânia, v. 34, n. 3, p. 173-180, 2004.

MESCHEDE, D. K. Relações entre o uso de herbicidas e sustentabilidade. In: YAMADA, T.; ABDALLA, S. R. S. Manejo sustentável na agricultura é discutido em Workshop na Esalq. Piracicaba: Potafos, p. 2-4, 2006. (Informações agronômicas, n. 116).

NUNES, U. R.; SANTOS, N. F.; FARNEZI, M. M. M.; ANDRADE JÚNIOR, V. C.; BRANDÃO JÚNIOR, D. S.; PEREIRA, G. D. Qualidade fisiológica de sementes de feijão em plantio direto sobre diferentes coberturas de plantas em Diamantina MG. Ciência Agrotécnica, Lavras, v. 31, n. 6, p. 1737-1743, 2007.

PASQUALETTO, A.; COSTA, L. M. Influência de sucessão de culturas sobre características agronômicas 
do milho (Zea mays L.) em plantio direto. Pesquisa Agropecuária Tropical, Goiânia, v. 31, n. 1, p. 61-64, 2001.

PAUluS, G.; MÜlleR, A. M.; BARCELlOS, L. A. R. Agroecologia aplicada: práticas e métodos para uma agricultura de base ecológica. EMATER/RS: Porto Alegre, 2000.

PERIN, A.; SANTOS, R. H. S.; URQUIAGA, S.; GUERRA, J. G. M.; CECON, P. R. Produção de fitomassa, acúmulo de nutrientes e fixação biológica de nitrogênio por adubos verdes em cultivo isolado e consorciado. Pesquisa Agropecuária Brasileira, Brasília, v. 39, n. 1, p. 35-40, 2004.

SECRETARIA DA AGRICULTURA E DO ABASTECIMENTO DO PARANÁ - SEAB. Área e produção: principais culturas do Paraná. 2008. Disponível em $:<$ http://www.seab.pr.gov.br/>. Acesso em: 22 dez. 2008.

SOUZA, C. M.; PIRES, F. B. Adubação verde e rotação de culturas. Viçosa: UFV, 2002. $72 \mathrm{p}$.

TEJADA, M.; HERNANDEZ, M. T.; GARCIA, C. Soil restoration using composted plant residues: effects on soil properites. Brazilian Journal Plant Physiology, Londrina, v. 18, n. 3, p. 389-396, 2008.

TOKURA, L. K.; NÓBREGA, L. H. P. Alelopatia de cultivos de cobertura vegetal sobre plantas infestantes. Acta Scientiarum Agronomy, Maringá, v. 28, n. 3, p. 379384, 2006.

WEIH, M.; DIDON, U. M. E.; RÖNNBERGWÄSTLJUNG, A. C.; BJÖRKMAN, C. Integrated agricultural research and crop breeding: Allelopathic weed control in cereals and long-term productivity in perennial biomass crops. Agricultural Systems, v. 97, n. 3, p. 99-107, 2008. 
Rosa, D. M. et. al. 